\title{
'My school has been quite pushy about the Oxbridge thing': voice and choice of higher education
}

Tina Byrom, Pat Thomson and Peter Gates University of Nottingham, UK

\begin{abstract}
Whilst government policies are now pushing teachers to listen to pupils, this concern is largely framed within the school improvement agenda. This is not the only arena where listening to pupils counts. This article examines the ways in which two young people, making a significant choice about which university to attend, felt unable to discuss their interests and concerns with their teachers. In one case, this resulted in a young woman doing less well in her examinations in order to avoid getting her first preference of Oxbridge, and securing her 'real choice' at another Russell Group university. The other was not invited by his school to apply to Oxbridge, despite a desire to go there which he felt unable to articulate at school. We suggest that, given the current concern over widening participation, these two cases provide hints that all is not well with school gate-keeping and career guidance procedures.
\end{abstract}

Keywords: empowerment, guidance, higher education, intervention

\section{Introduction}

Following the Education Act of 2002, an increased emphasis was placed on schools to provide pupils with opportunities to become 'more active participants' (DfES, 2004: 2) in decisions that directly affected them. This aim has largely been met through the school improvement agenda, which has resulted in myriad pupil involvement activities within schools. Such activities include those that seek to include pupils in, for example, school governance, the appointment of new school staff, school councils or committees and peer mentoring schemes (Thomson and Holdsworth, 2003; University of Nottingham, 2006).

Literature on pupil voice raises important issues concerning the ways in which pupil voice activities may legitimate particular voices. For example, questions concerning 'who' participates and who is listened to, have frequently arisen (Fielding, 2001; Fielding and Rudduck, 2002). In addition, the close association that pupil voice has had with the school improvement agenda has led to rather limited usage and understandings of its full potential in empowering pupils. It has been, in the words of MacBeath (2006), too frequently experienced as pupils 'having a say within the bounds of school convention' (p. 105). 
This article explores the ways in which 'school convention' influenced the decisions that two students made concerning their higher education choices. We suggest that while schools are committed to helping students make decisions about which universities to put on application forms, the commitment to 'advice' seems to outweigh the simple practice of listening. We argue that although schools may now seek to increase pupil involvement in various aspects of school improvement, there are other arenas where pupil voice matters. One such instance is when students are looking at prospective universities.

We begin by outlining the methods used in the research and the principles of pupil voice which underpin the article.

\section{Context of the research}

This article draws data from an ESRC-funded doctoral study that focused on the educational trajectories of 16 students moving from the final year of school into university. The study reflects current government policy agendas, which place an emphasis on widening the participation of young people from low socio-economic backgrounds in higher education. As 'targeted' individuals, all 16 students participated in a Sutton Trust Summer School held at the University of Nottingham. The Sutton Trust programme aims to provide additional support for non-traditional university entrants to help them decide whether to attend university or not and also provides advice on which universities to apply to.

\section{Methods}

The students in the sample are currently entering their second year of undergraduate study. However, at the time of the study they were just beginning their final year of school. The Sutton Trust provided an opportunistic case through which to examine the experiences of a group of young people who did appear to be interested in higher education. With permission of The Sutton Trust, the study was explained to the group attending the summer school and volunteers were asked to join the study. Sixteen agreed to take part.

The study aimed to explore students' understandings of their experiences as they began the process of applying to university and as they lived through their first term as undergraduate students. It required methods that illuminated their life trajectory/ies complete with constraints, opportunities presented, influences, critical moments and outcomes. This was in accord with Creswell's (1998: 13) notion of qualitative research as an 'intricate fabric composed of minute threads, many colours, different textures, and various blends of material' where the fabric 'is not explained easily or simply'. The methodological approaches utilized also attempted to empower the students: as they told their respective stories of how they came to make the decisions they did concerning higher education, they had a 'voice' in the research. The extensive use of narrative quotations and the (re)presentation of 'stories' are strategies which attempt to show experiences from the students' points of view, using their words.

All of the young people involved in the study were initially invited to the University of Nottingham for focus group interviews. Of the 16, eight stated that they would be prepared to attend the day (seven attended). The group was divided into two smaller groups and each group rotated through three planned activities: two focus group interviews, an individual activity and one-to-one interviews. 
The first focus group discussion was based around the following themes: family, hobbies, going to university (motivation, prospectuses, application process) choice of sixth form, friends, education and the future. The second focus group discussion was based around the theme of 'background' and social class. Each young person was also invited to complete a family tree and go to a 'Big Brother' style video diary room where they could record anything they wanted to say about themselves, the process of going to university or something about the day itself. All interviews were recorded on video. The remaining young people, who were unable to attend the day, were interviewed individually in their school or college sixth form. In addition to the planned interviews, email communications were exchanged at various points throughout the research and journals completed during their Sutton Trust experience were also available for analysis.

This article draws on data from the focus groups, individual interviews, email conversation, video diary room and journals.

\section{The principles of pupil voice}

Much pupil voice work in schools centres on school governance issues through which opportunities are provided for pupils to become involved with decisions that directly affect them. Fielding (2001) argues that such pupil voice activities centre on:

- Speaking

- Listening

- Skills

- Attitudes and dispositions

- Organizational culture

- Spaces and the making of meaning

- Action

Fielding raises a number of concerns about each of these activities, suggesting that in many instances students may speak, but not be listened to, and if listened to, nothing may happen as a result. We do not intend to reiterate all of the issues raised by Fielding, but will instead focus on the questions that are most pertinent to this article: that is, whether students have the opportunity to speak about the things that matter to them, and if they do speak, whether anyone really listens.

Our usage of pupil voice extends beyond the collective and institutional interests of school improvement and moves towards more individualized notions of voice, where the articulation of voice has increased relevance to individuals. Arnot (2004) addresses this kind of voice, and outlines the way in which young people use the language of self where the 'language of individualization, the concepts of freedom and choice' are used to 'justify their choices and decisions' (Arnot, 2004: 1). That is, individual students not only determine and make choices about their own life course, but literally speak it into existence. Thus choice and voice, in the context of a 'reflexive biography', become one (Dwyner and Wyn, 2001).

However, this kind of reflexive voice is not used in a vacuum. The context within which such individualized voices are articulated is important. Students may feel more able to say what they think and feel in some circumstances than others. Their relative ease or discomfort has to do with the general institutional ethos, the general personal and pedagogical 
relationships between students and teachers, students and other students and specific events, which shape the conversations.

The expression of individual voice thus goes back to the important consideration of the potential of pupil voice activity, namely, whether it is seen as 'an additional mechanism of control' (Fielding, 2001: 100) or as the democratic expression of citizens within a school community.

\section{Choosing a university}

A number of sources influence pupils' choices and decisions concerning higher education. For example, family and friends have some bearing on the university choices of students (Brooks, 2003) and what is available in the education marketplace also has a significant impact on what decisions are able to be made (Ball, 2003). This article takes these as a given and looks specifically at the role of the school in higher education choice and how choice is merged with the notion of voice. To do so, it takes two 'cases' where the students found it impossible to articulate their own thoughts and feelings about university choice within the confines of their respective schools. Their experiences seem to go against the current wave of interest concerning pupil voice in schools.

\section{Unheard voices}

The title of this section reflects the difficulties students in this sample had in articulating their thoughts about university. Their voices went 'unheard' because they did not feel sufficiently empowered to articulate them.

The first story - that of Erin - reflects issues about Oxbridge that were consistent across the sample. This story sits in a body of literature that focuses on the notion of 'fit' (e.g. Archer and Hutchings, 2000; Bowl, 2003; Burn, 2001; Reay, 2001; Wentworth and Peterson, 2001), where university choice is indicative of wider social and cultural influences. As a result of not feeling able to articulate her thoughts, Erin resorted to indirect means to ensure her 'real choice' of university was secured.

Tim's story also illustrates the way in which voices become silenced within an 'organizational culture' (Fielding, 2001), which has specific procedures in place for dealing with university applications. His story goes some way in demonstrating how dominant voices, that is, those of teachers, can restrict students' higher education choices.

We now turn to Erin and Tim's schools and provide some background contextual information about them before going on to tell their stories.

\section{Two contrasting schools}

In providing further contextual information about Erin and Tim's schools, we do not intend to offer comparisons in the sense that one is 'better' than the other. We provide them to offer two contrasting framings of the students' experiences.

Erin and Tim attended disparate schools ${ }^{1}$ as summarized in Table 1.

In progressing into the sixth form, Erin was one of a few students, whereas in Tim's school, the majority of students decided to take AS and A2 levels. 
Table: Context of two schools

Erin's school

- Comprehensive college holding specialist status for technology since 2002

- Pupils come from full range of socio-economic background

- Free school meals just below average

- College is in an area of deprivation with some incomes just above the eligibility line

- Small number of pupils in care

- Attainment on entry is below average

- Statemented pupils above average

- '[Marlow] is a good and effective college which has shown consistent improvement and provides a high quality of education for its pupils and students.' (Ofsted)

- Recognized for adding value

- AS/A2: 92\% Pass rate

- $(23 \%$ high grades $\mathrm{A}-\mathrm{B})$
Tim's school

- Oversubscribed

- Attainment on entry is well above the national average

- Wide catchment area which includes wards which have a higher than national percentage of high social class households

- Less than 5\% free school meals (below national average)

- $\quad$ Percentage of EAL high, but all are fluent in English

- $\quad$ SEN and statemented pupils below national average

- $\quad$ 'Cavendish] is a most effective and very good school with many impressive features.' (Ofsted)

- Above average AS/A2 results

- Well above average GCSE results

\section{Erin's story: Oxbridge as a step too far}

Erin had always believed she would go to university. Her father is a vicar and had attended theological college. Her participation on the Sutton Trust programme for students from low socio-economic backgrounds was justified by his low salary and the context of her school. She attended a school which served an area that suffers from high levels of deprivation (2004 Ofsted). Ofsted stated that the school was one of 92 in the country that had achieved 'Most Added Value' and 'Most Improvement' in 2003 examinations.

In this school and family context, Erin felt under pressure to do well. Because she achieved well at GCSE, she had now joined a small group of students who were expected to progress onto A2 level and achieve good results.

I feel at school there is a lot of expectation or pressure on us. I think if you have performed well at GCSE, the teachers seem to EXPECT you to do well at A level, and that it will be easy to succeed. (Erin, email)

The school expectation that Erin would do well extended to the type of university she should apply to. She felt compelled and frustrated by the pressure she was under to apply to Oxbridge.

My school has been quite pushy about the Oxbridge thing. They want you to apply to make you look good and to make them look good. It annoys me how they only care about themselves. (Erin, video)

Erin resented the position she was placed in. She knew that should she attend Oxbridge it would make 'them look good': this school pressure was one manifestation of the market-based education system built around a school's position in the league tables. If the school had students entering elite institutions, then this was a signifier of a clearly 'good 
school'. Such a 'good' reputation could well play out in further enrolments of aspiring and academically capable students and, even better, inspection reports.

Erin, however, felt that her own anxieties concerning Oxbridge were considered invalid within this context. She certainly felt that as an academically able (as evidenced by her examination performance) student, she should be applying to Oxbridge, yet she also felt reluctant to do so. She secretly wanted to go to another Russell Group ${ }^{2}$ university. She felt unable to explain or justify her reluctance to her teachers as she thought that she would be 'letting them down' if she did not apply. They would not understand why she would not go to the 'best' institution if she could.

Erin dutifully studied universities through guides, league tables, open day visits, and interviews. The Sutton Trust assisted here, and with their help, Erin felt guided into making appropriate choices, that is, to apply to prestigious universities. Although Erin did not feel 'pushed' into particular institutions, the information delivered during the week focused only on traditional universities (focus group discussion). This focus is in line with the aims of the Sutton Trust week where students from non-privileged backgrounds are encouraged to apply to 'top class' universities (Lampl, 2005). In this context, Erin felt supported in her 'real choice' of a Russell Group university and yet continued to feel 'uneasy' about the status and prestige attributed to Oxbridge and her own internal dilemma of whether she should apply or not. Erin just knew that she wanted to go to the University of the North and had been since her involvement in this research project began (November 2004). Throughout her final year at school, she felt torn between this feeling and the pressure placed upon her to go to Oxbridge.

Despite her reluctance, Erin did apply to Oxbridge and received an acceptance letter. She also received an acceptance letter from her favoured university. Her response to the Oxbridge letter directly contrasted with her response to other acceptance letters she received and her interview experience at universities where she felt more at home (e.g. the University of the North) as illustrated in Figure 1. Her response to the Oxbridge letter was far from the excitement she felt about the letter from the University of the North. It was sobering; Erin knew that the decision she would make would not be easy.

The sense of enthusiasm expressed about the University of the North ('happy' and 'excited') was lost in the prospect of making a difficult decision. Erin's use of the words 'thinking long' and 'hard' is indicative of the emotional labour that lay behind the decision.

Still unable to make a final decision about which university to attend, Erin placed Oxbridge as her confirmed choice and the University of the North as her insurance place. Further reflecting her inability to make the decision about where to go, she decided to hand over her fate to A2 level examination results, as exemplified in the following journal entry.

This was in fact the easy way, in effect I did not decide - I decided to let my results decide. I felt I was under a lot of pressure from my school to go to Oxbridge but I came to the conclusion was I should just do my best and what will be will be. (Erin, journal)

Erin felt unable to exercise her 'voice' in the light of the school pressure she felt to go to Oxbridge. She was convinced that her teachers would not understand her 'intuitive' feeling that the University of the North was just a better place for her to be. She felt at home there. There were people there 'like her' - and this was not the case with Oxbridge, where she felt out of place and uncomfortable. 


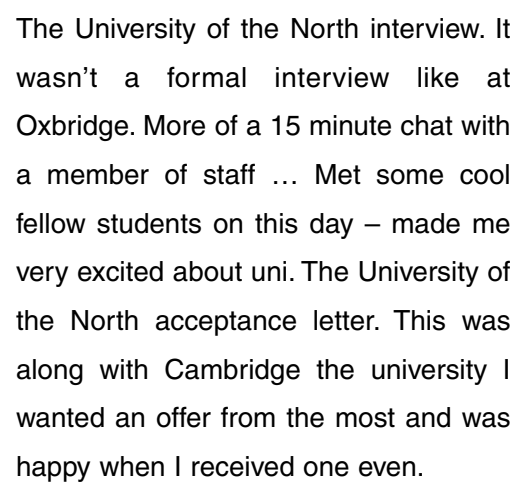

Oxbridge acceptance letter. I cannot deny I was very shocked and excited when I received this. I felt very proud but in a way it made the decisionmaking process much harder as I never expected to receive an offer from Oxbridge and I realized I would have to think long and hard about whether I really want to go to this place.

\section{Figure 1: Comparison of responses to acceptance letters: Erin}

However, she got her voice 'heard' using more indirect and potentially self-damaging strategies. Erin knew that she had to obtain three As at A2 level to enter Oxbridge and she therefore decided the only thing she could do was to jeopardize her examination results by not working as hard as she should.

\footnotetext{
Now the more I think about it I actually really want to go to the University of the North so I think that subconsciously I perhaps am not working my hardest or am willing to let myself get an A and two Bs so I can go to the University of the North and not Oxbridge! (Erin, journal)
}

In this way, Erin was able to exercise her voice in her journal, and act on it through indirect means. Unable to literally express her feeling about what she really wanted, in the face of the school pressure to 'go for the best', she used an alternative and devious means of ensuring she got what she wanted. She knew that her teachers would not berate her for not doing as well as they thought she should - there would be no consequences for achieving less than expected results. Doing well, but not too well, seemed like the best strategy.

Erin had never felt completely comfortable with the idea of going to Oxbridge and felt justified in 'under performing' so that entry there would never become a possibility. Despite the potential of an ideal 'academic' fit, where she would attend lectures and tutorials with students as well qualified as she was, the pull of a 'social' fit, where she was with peers within whom she felt at ease, influenced her decision to sabotage her examination results.

Her inability to articulate her true feelings about Oxbridge are indicative of the power relations that operated in her school. There is a sense in which Erin got caught up in what her teachers wanted for her. She was unable to directly oppose their authority and pressure.

The issue of Oxbridge was not the only instance where Erin felt unable to articulate her own wishes. Following her History AS results in which she obtained an A grade, the whole class were entered to re-take a module. Erin 'just went along with it' (Results 
Pro-Forma Sheet) without question, even though she had achieved well. She did the same in respect to the Oxbridge application. She 'went along with it' because it was expected of her.

Erin's story provides some insight into how students can defer to their teachers' authority, despite their own growing autonomy and independence. They are silent and inarticulate, and it seems, are not offered an occasion where they can speak up. There was no space or place in which to even discuss the important issue of university choice.

We now turn to Tim who offers a different example of how choosing voices can be constrained in schools.

\section{Tim's story: I wasn't 'invited' to apply to Oxbridge}

Tim presented an interesting 'case' in this study. He lived in an affluent area in the south of England, although a class classification based on parental occupation, might position him as skilled working class. He went to a single-sex school described by Ofsted as 'a most effective and very good school with many impressive features' and where GCSE results were 'well above average' and AS and A2 results 'above average'. ${ }^{3}$ In that context, once at secondary school, Tim believed that going to university would be a 'natural progression' (Tim, focus group discussion). Tim aspired to become a doctor although he was taking an alternative route towards that career trajectory. He wanted to study a generic science course at university to 'keep his options open'. He understood the education market, and appreciated the 'need' to apply to a top university. His thinking about this issue demonstrates the way in which he attempted to negotiate through the complexities of the higher education market - trying to tease out what the 'best' was.

\footnotetext{
...Generally thought of the ones that achieve highest in league tables, but depends on your view. One of the factors to me is, is the top place I can go, but then I guess you get the question of 'what defines the top place you can go?', somewhere where I like, and will feel compatible but also looking at entry requirements, and looking at which universities scored highest for your particular subject, not just generally. (Tim, email)
}

Tim, like Erin, understood the education market and sought out what he considered to be prestigious universities. He looked up the position of institutions and subjects he was considering to ensure he applied to a reputable institution. When asked what influence the Sutton Trust week had on his decision-making, Tom suggested that the week had confirmed and legitimated his choices: they were in line with the focus of the Sutton Trust week as he was considering six Russell Group universities.

However, Tim wrestled with many ideas concerning university. He wanted to be 'compatible', that is be somewhere he felt at home, but his choices were driven by the idea that some universities 'scored highest' for his particular subject. Although he was encouraged by his school to go to university, Tim expressed frustration that he was not invited to apply to Oxbridge in his school where, 'there was an expectation on some to apply to Oxbridge' (Tim, interview 2). During his second interview, Tim detailed how students were invited to apply to Oxbridge and he had not been selected as one of the few. Indeed, he felt there was a cloud of mystery hanging over the Oxbridge issue, He couldn't understand how it was that some students got to be invited to apply, while others didn't. 
I don't know why to be quite honest with you. I'm quite upset about that. Certainly I know some were expected to apply to Oxbridge, so one of my friends who's actually here now, he was apparently, he didn't actually tell me, but my mum's his mum's friend, he was expected to apply. (Tim, interview 2)

Tim did not understand his friend's silence, or his teacher's reluctance to 'invite' him to apply. Although he admits he 'could have done it anyway' (Tim, interview 2) he implies that his choice of university was somewhat out of his control.

This lack of agency in the face of school action is reminiscent of Erin's story. She too went along with her teachers' advice, despite her own reservations. Tim is academically able in the narrow sense - he achieved well in examinations both at GCSE and AS level. His 'academic credentials' (Naidoo and Jamieson, 2005) are impressive and would seem to appropriately equip him for the rigour of academic study at Oxbridge. He believed he would 'fit' academically. And yet his teachers appeared not to see this, and he did nothing to change their minds.

In Tim's story, we get a glimpse of how students capable of entering Oxbridge are treated differently in at least one school. He was frustrated at the quality of the school form tutor statement on his own application. Tim acknowledged that if he had gone with his own instincts and had applied to Oxbridge, his personal statement would have been written by 'the Oxbridge tutor' in the school and therefore would have been 'better' (Tim, interview 2).

Tim's conviction that he was suited to Oxbridge and that he could have applied didn't extend to his perceptions of likely success in the application process. He stated that he 'probably wouldn't have got in anyway' (Tim, interview 2), This was perhaps a vindication for his non-actions: there was no point really in challenging the school's rejection of him as a suitable Oxbridge candidate. Perhaps the teachers were right after all.

However, even if Tim's prognosis of his likely candidature is correct or not, there is little doubt that he felt constrained by his teachers' choice. He deferred to their knowledge of the education system and allowed them to direct him towards alternative higher education institutions. He conceded his right of choice to them.

Although relatively happy with the outcome, Tim also reflected on what could have been. During the last formal meeting of the research project, he reflected on his university experience as a missed opportunity. He confirmed his belief that he should have had the courage to approach his teachers to question them about the Oxbridge issue. His results, three As at A2 level, suggest that there might have been some truth in his assessment of his ability and suitability for Oxbridge.

These two contrasting stories reveal complexities in the way schools direct students into higher education. Although Erin and Tim presented themselves as independent individuals capable of making decisions that directly affected them, they both experienced constraints in terms of their university choice. Neither Erin nor Tim felt sufficiently confident in approaching their teachers to discuss the issue of Oxbridge. Opportunities to engage in meaningful dialogue concerning university choice with their teachers did not materialize. These two stories raise questions about the ways in which schools can influence students' decisions and constrain their reflexive voices: a particularly pertinent concern within the current climate of widening participation in higher education. 


\section{The discomfort of voice}

The two stories hint that all is not well with school gate-keeping and career guidance procedures - an arena where pupil voice matters as much as in broader questions of school improvement.

Erin and Tim represent academically successful students; they have a string of excellent qualifications behind them. They are articulate and confident. They do not challenge their schools - to the contrary they are exactly the kinds of 'successes' that schools attempt to produce. They should not, it seems, have had any difficulty in asserting their wishes about university choice. And yet they did.

In Erin and Tim's stories, we get a glimpse of how 'institutional practice' worked to influence their university choices. Everything in their schools was positioned to support the 'best' students to go to Oxbridge. In Erin's school, where there was only a handful of students likely to get the results for elite higher education, this was the whole group. In Tim's case, where he was one of a comparatively large number of appropriately qualified students, the school sifted out those students who they deemed to be most likely to succeed in the application process. In both cases then, the school acted as the primary 'chooser' and gate-keeper to higher education.

We also see how both Erin and Tim felt unable to articulate their 'real choice' universities. Their incapacity to question what their teachers said was uncharacteristic - Erin and Tim were both articulate and had strong opinions concerning university. However, the issue of Oxbridge was a thorny issue for all the students in this sample. Like Erin and Tim, all of the other students in this study also felt disempowered when thinking about Oxbridge and the notion of 'fit' featured in many of their stories about university. All students felt that Oxbridge was 'too much to hope for' and the prospect of applying there raised many questions of their sense of identity and worth. Many self-eliminated (Bourdieu and Passeron, 1977) from Oxbridge on the basis that there was an insufficient social fit - they just wouldn't feel comfortable and wouldn't get in. Erin followed this pattern and identified an alternative Russell Group university where she felt more 'at home'. Tim offers a different experience and his ambitions of applying to Oxbridge were quashed by the institutional practices within his school and his reluctance to question those practices.

These are cases which show how schools maintain power relationships that position students as 'novice' choosers. Such positioning effectively leads to students being 'relatively passive' in 'institutional processes' (Giddens, 1991: 75) at a critical transition point in their lives where articulating their own thoughts is of importance. As Devine notes:

Power is enforced through the use of judgements by teachers ...who through their knowledge and expertise, evaluate reward and normalize behaviour via their institutional practice. (2003: 113)

The privileging of teacher voice over that of students (re)produces relations which favour some more than others. While in the instance of Erin and Tim it did not matter a great deal, it is highly likely that other less well qualified students may not have been as fortunate with the steerage of their choices.

\section{What this means for pupil voice}

The practice of listening to the views of pupils and students is gathering momentum within schools and colleges. As we have outlined above, much of the focus of pupil 
voice links closely with school improvement. It seeks to empower pupils from all spectra of social life and engage them in education. In that sense, much of the pupil voice agenda operates in emancipatory ways, attempting to draw in disengaged learners (see, for example, Atweh and Bland, 2004).

This article has moved away from this focus and instead has highlighted an additional arena where pupil or student voice (as Carol Robinson and Carol Taylor identify in this special issue, these terms are often used interchangeably in relation to pupil voice work) matters. The students in this study are not disengaged with education - they clearly view it as a way to improve in life and their voices in that sense are congruent with that of their respective institutions. However, there is a clear gap in the pupil voice literature concerning the ways in which schools influence students' university choices and the lack of space available for students to discuss their fears, hopes and desires with their teachers.

Most importantly, this study has illustrated how schools can influence the university choices of pupils. Students in this study did their own research about higher education. They brought this knowledge into school where it was generally legitimated because they were successful and capable students. However, the exception was in relation to the choice of Oxbridge where the advice - to go or not to go - that was offered by form teachers was strongly shaped by institutional circumstances, including market position and reputation, and size of the final year cohort. Individual teacher assessments about potential and suitability also came into play.

While this might in part have been, as the TES puts it, because 'teenagers are let down by "patchy career advice"” (Times Educational Supplement, 2006: 3), Erin and Tim's stories suggest that this is too simple an explanation. Higher education choice is not simply improved because teachers know more about the options. The power relations of schooling prohibited the students in this study from offering their opinions and exercising their preferred choices. Their 'voice' was unheard. If Tim and Erin were to get their way, then they had to have some say as well.

We can only speculate about how this teacher voice/choice plays out in the case of less well qualified students. What steer are they being given? What decisions are being made on their behalf about what courses they should do and what institutions they should apply to?

\section{Conclusion}

Whilst the focus of this article has been on only two school contexts and two students, the experiences of Erin and Tim illustrate the ways in which students potentially have limited agency when deciding on their choice of university. It also hints at the ways in which students are subjected to the specific cultures and expectations of their school.

In the current climate of pupil voice activities and the need for schools to listen to its pupils, the process of university choice presents an important opportunity for teachers to engage in meaningful conversations with their students. Space is required for students to question their teachers' perspectives and opinions, rather than students relinquishing their capacity to choose and deferring to the knowledge and experiences of teachers.

The authors can be contacted by email at: tina.byrom@nottingham.ac.uk 


\section{Notes}

1 Information taken from the respective Ofsted reports.

2 The Russell Group comprises: Oxford, Cambridge, Nottingham, Warwick, Birmingham, Bristol, Cardiff, Edinburgh, Glasgow, Imperial College of Science, Technology and Medicine, King's College London, Leeds, Liverpool, London School of Economics and Political Science, Manchester, Newcastle, Sheffield, Southampton and University College London - all are research intensive universities.

3 I am unable to provide the URL for this report to ensure participant anonymity.

\section{References}

Archer, L. \& Hutchings, M. (2000) 'Bettering yourself?' Discourses of risk, cost and benefit in ethnically diverse, young working-class, non-participants' constructions of higher education. British Journal of the Sociology of Education, 21(4), 555-74.

Arnot, M. (2004) Educating Learner-Citizens for Social Change: A Gendered Approach to Citizenship Education in Contemporary Society. The Positioning of Education in Contemporary Knowledge Society. Reykjavik.

Atweh, B. \& Bland, D. (2004) Problematics in young people as researchers: visions and voices. In Proceedings Social Change in the 21st Century, Queensland University of Technology - Carseldine.

Ball, S. (2003) Class Strategies and the Education Market: The Middle Classes and Social Advantage. London: RoutledgeFalmer.

Bourdieu, P. \& Passeron, J. (1977) Reproduction in Education, Society and Culture, trans. R. Nice, 2nd edn. London: SAGE.

Bowl, M. (2003) Non-Traditional Entrants to Higher Education: 'They Talk about People Like Me'. Stoke on Trent: Trentham Books.

Brooks, R. (2003) Discussing higher education choices: differences and difficulties. Research Papers in Education, 18(3), 237-58.

Burn, E. (2001) 'Good girls are seen and not heard': a white working-class woman's educational story. Paper presented at the British Educational Research Association Annual Conference, University of Leeds, 13-15 September.

Creswell, J. (1998) Qualitative Inquiry and Research Design: Choosing Among Five Traditions. Thousand Oaks, CA: SAGE.

Devine, D. (2003) Children, Power and Schooling: How Childhood is Structured in the Primary School. Stoke on Trent: Trentham Books.

DfES (2004) Fair Admissions to Higher Education: Draft Recommendations for Consultation. London: DfES Publications.

Dwyner, P. \& Wyn, J. (2004) Youth, Education and Risk. Facing the Future. London: RoutledgeFalmer.

Fielding, M. (2001) Beyond the Rhetoric of Student Voice: new departures or new constraints in the transformation of 21st century schooling? Forum, 43(2), 100-10

Fielding, M. \& Rudduck, J. (2002) The transformative potential of student voice: confronting the power issues. Paper presented at the annual British Educational Research Association, Exeter, September.

Giddens, A. (1991) Modernity and Self-Identity: Self and Society in the Late Modern Age. Cambridge: Polity Press.

Lampl, P. (2005) State School Admissions to our Leading Universities: An Update to 'The Missing 3000'. London: The Sutton Trust.

MacBeath, J. (2006) Finding a voice, finding self. Educational Review, 58(2), 195-207.

Naidoo, R. \& Jamieson, I. (2005) Empowering participants or corroding learning? Towards a research agenda on the impact of student consumerism in higher education. Journal of Education Policy, 20(3), 267-81.

Reay, D. (2001) Finding or losing yourself? Working-class relationships to education. Journal of Education Policy, 16(4), 333-46.

Thomson, P. \& Holdsworth, R. (2003) Theorizing change in the educational 'field': re-readings of 'student participation' projects. International Journal of Leadership in Education, 6(4), 371-91.

Times Educational Supplement (2006) FE Focus, 6 October, p. 3.

University of Nottingham (2006) Engaging Critically with Pupil Voice: Background to the Series, accessed June 2006.

Wentworth, P. \& Peterson, B. (2001) Crossing the line: case studies of identity development in first-generation college women. Journal of Adult Development, 8(1), 9-21. 